\title{
A novel five-level voltage source inverter interconnected to grid with srf controller for voltage synchronization
}

\author{
Bogimi Sirisha, Mohd Abdul Nazeemuddin \\ Department Electrical, University Engineering College (A), Osmania University, Hyderabad, Telangana 500007, India
}

\begin{tabular}{|c|c|}
\hline Article Info & ABSTRACT \\
\hline Article history: & Power utilization from renewable sources with efficient modules is very \\
\hline Received Jul 27, 2021 & vital. Maitaining harmonics below specific standard during grid \\
\hline Revised Sep 15, 2021 & inverter which is controlled by synchronous reference frame (SRF) \\
\hline Accepted Dec 22, 2021 & $\begin{array}{l}\text { controller for grid interconnection and synchronized power injection. The } \\
\text { input of the converter is integrated with renewable energy source }\end{array}$ \\
\hline Keywords: & $\begin{array}{l}\text { photovoltaic arrays (PVA) for the injection of renewable power into the grid. } \\
\text { For constant voltage input, the PVAs are connected to a booster converter }\end{array}$ \\
\hline $\begin{array}{l}\text { Maximum power point tracking } \\
\text { algorithm }\end{array}$ & $\begin{array}{l}\text { controlled by the maximum power point tracking (MPPT) algorithm. The } \\
\text { design is analyzed with different operating conditions by changing the load } \\
\text { type (static and dynamic) using MATLAB/Simulink software. Graphical }\end{array}$ \\
\hline Photovoltaic array & comparisons are taken for the analysis with the help of 'powergui' toolbox \\
\hline Point of commoncoupling & available in the software. \\
\hline
\end{tabular}

Synchronous reference frame
This is an open access article under the $\underline{C C B Y-S A}$ license.

\begin{abstract}
Power utilization from renewable sources with efficient modules is very vital. Maitaining harmonics below specific standard during grid inverter which is controlled by synchronous reference frame (SRF) controller for grid interconnection and synchronized power injection. The For constant voltage input, the PVAs are connected to a booster converter controlled by the maximum power point tracking (MPPT) algorithm. The type (static and dynamic) using MATLAB/Simulink software. Graphical available in the software.
\end{abstract}

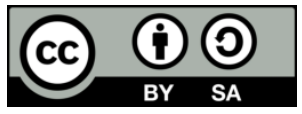

\section{Corresponding Author:}

Bogimi Sirisha

Department Electrical, College of Engineering (A), Osmania University Main Rd

Amberpet, Hyderabad, Telangana 500007, India

Email: wichian.sit@mfu.ac.th

\section{INTRODUCTION}

Demand for electrical energy generation is growing day by day with an increased consumption by various loads across the globe. More and more power production from traditional methods (diesel generators, thermal plants, and nuclear plants) is damaging the environment as these ways of generation produce hazardous waste and gases. These power plants play a vital role in the increase of global warming making earth a bad place for the survival of living things on the planet. Better ways of generation through renewable sources are the only option of the future to protect the planet and make it a better place. These ways of generation include hydropower plants, solar plants, wind farms, biogas plants, and tidal wave units. From all the mentioned renewable power generation methods hydropower plant is considered to be a huge power generating plant that can be utilized for the load demand [1]-[6]. However, the capital cost for the plant installation is very high and the construction time takes years which is the major drawback for this way of generating power. The immediate replacement to the hydropower plant is a wind farm which also generates huge power but can be installed in specific areas far from civilization. Solar plants are the optimal option for power generation either in huge or low amounts.

Solar plants are installed using a set of multiple photovoltaic planes which generate direct current (DC) power by utilizing solar irradiation. Different parallel and series combinations of these panels are called photovoltaic arrays (PVA). The DC power from the PVA needs to be converted to either single-phase alternating current (AC) or three phases AC as the loads run on AC voltage. More research is taking place on this conversion process with different converters for better efficiency and reduced harmonic generation [7], [8]. The traditional multi-level converters include cascaded, diode clamped, flying capacitor, modular, and 
which have control issues and complicated circuits [9]-[13]. In previous researches conventional voltagesource inverter (VSI) are used for the transformation of DC voltage of the PVA to AC voltage for injection into the grid. The conventional six-switch VSI (two-level) has high harmonics generation and needs large inductor capacitor (LC) filters for the reduction of these harmonics. This increases the installation cost of the PV plant as huge power needs to be transmitted. The general control unit used for the inverter is unit vector template feedback control which takes input from the grid voltages only. This conventional converter and controller are replaced by a novel five-level VSI and synchronous reference frame (SRF) controller with feedback from the grid voltages, currents, and DC voltage of the inverter. In section 1 the introduction of the proposed topology and drawbacks of traditional power generation is discussed followed by section 2 which includes the converter working principle and control structure of the converter. Section 3 includes PVA module modeling with the MPPT algorithm. Section 4 has simulation results of the proposed system with results generated in graphical representation for different load conditions. The final section 5 has the conclusion of the paper followed by references.

\section{NOVEL FIVE-LEVEL VOLTAGE SOURCE INVERTER}

A five-level VSI shown in Figure 1, which increases the number of levels for the given switches. The interconnected capacitors create stabilized output voltages with reduced overshoots in the output. The inputs are two DC sources with half the voltages $\mathrm{V}_{\mathrm{dc}} / 2$ connected through a common neutral point. These DC sources are further replaced with PVA units for the utilization of renewable energy. The key feature of this topology is that the number of diodes for clamping is reduced as compared to diode clamped inverter and the numbers of capacitors are reduced as compared to flying capacitor inverter. The converter also does not require any a DC source that is isolated at the input for regenerative purposes. The converter control is updated with the SRF control module which generates reference signals making the converter work in synchronization to the grid.

Each leg of the proposed converter contains eight switches, with four legs in each phase area. Four switches in the top section create positive multi-level voltage, while four switches in the bottom part generate negative multi-level voltage. The voltage splitting capacitors C1, C2, and C3 generate different voltage levels for the switching. As can be seen, the clamping diodes required is lower than in a diode clamped inverter, and the number of capacitors is lower than in a flying capacitor inverter [14]-[16]. For regenerative applications, the converter need not uses a DC source that is isolated at the input. $\mathrm{Cx} 1$ and $\mathrm{Cx} 2(\mathrm{X}=\mathrm{a}, \mathrm{b}, \mathrm{c})$ capacitors are charged.

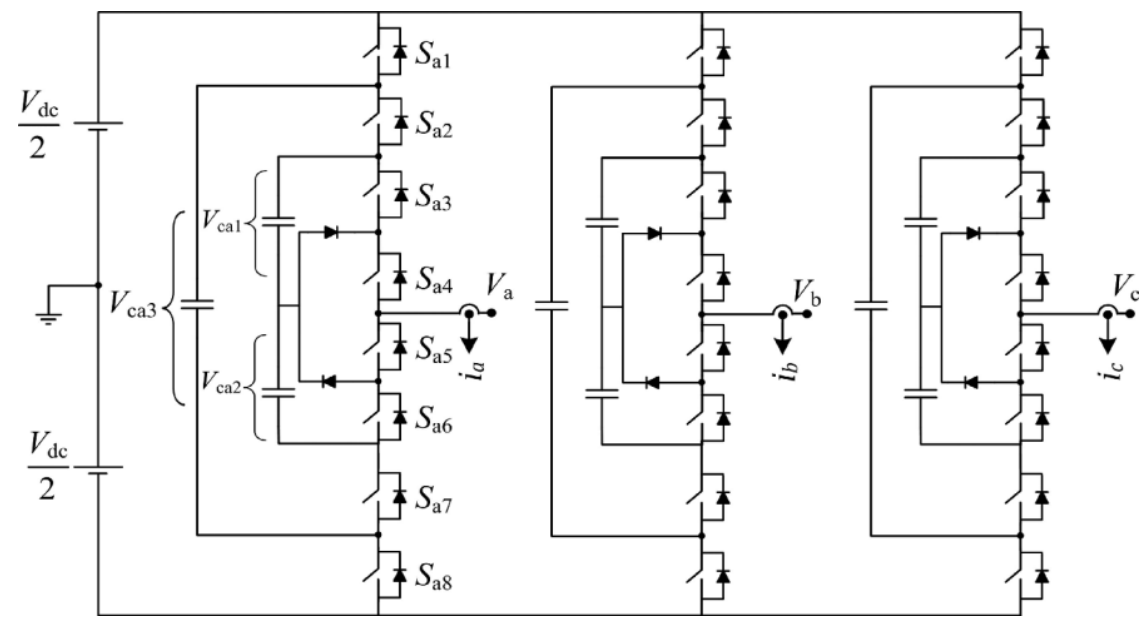

Figure 1. Five level novel VSI topology

\subsection{Behavior analysis of capacitor voltages}

As can be observed the five-level voltages including zero voltage are generated as per the switching of the eight switches of one leg. The zero voltage level includes discharging and charging of capacitors for achieving voltage across capacitor equalizing making the converter redundancy to voltage variations. The above switching states are achieved by sinusoidal PWM technique with reference sin waveform compared to four level-shifted high-frequency triangular waveforms as in Figure 2. 


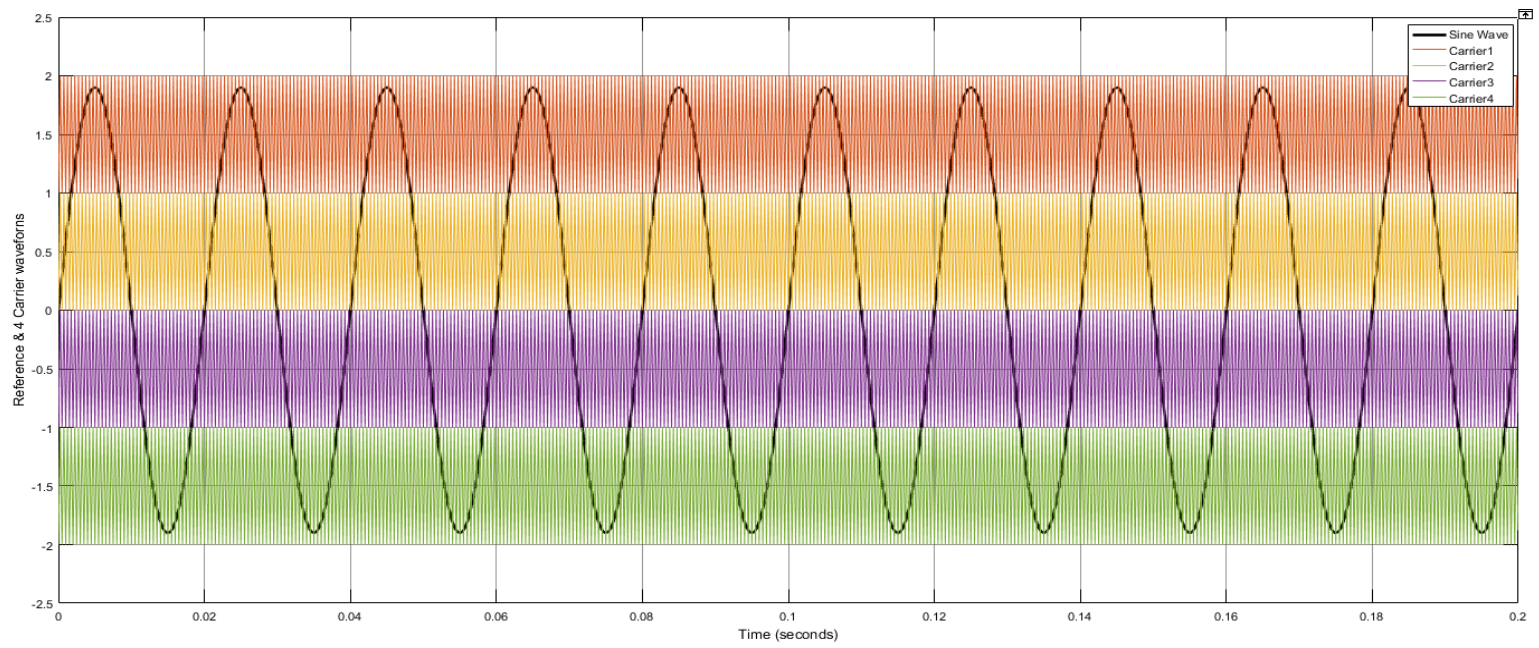

Figure 2. Sine PWM technique for the generation of switching states for the proposed converter

The above method employed for the generation of pulses is the In-phase disposition (PD) carrier modulation technique. In this method, all the carrier waveforms are in phase with no phase shift [17]-[19]. The reference sin waveform for the above PD modulation technique is generated by the SRF controller which generates a reference signal in synchronization to the grid.

The redundancy of switching states at levels $1,2,3$ to discharge and charge capacitors. However, there are no redundancy switching states at the 0,4 levels. Managing capacitor voltages $\mathrm{Cx} 3$ and $\mathrm{Cx} 2$ is best done at level 1, while controlling capacitor voltages $\mathrm{Cx} 3$ and $\mathrm{Cx} 1$ is best done at level 3 . There are also redundancy states at levels 1,2 , and 3 . Depending on the output current direction, each redundancy state with three capacitors to discharge or charge. As a result, the difference between nominal and measured levels of voltage will be reduced. Consider the following scenario: the output level to be achieved is 3 , and capacitor Cx3 must be charged. Furthermore, if the currents going in and out of the capacitors to discharge and charge the capacitors $\mathrm{C}_{1}, \mathrm{C}_{2}$, and $\mathrm{C}_{3}$ are not regulated, the flying capacitors voltage may differ from what was expected. Table 1 gives the balancing technique of voltage by utilising switching states.

Table 1 Balancing of voltage technique for each inverter phase

\begin{tabular}{|c|c|c|c|c|c|c|}
\hline Output level & Condition & $i_{\mathrm{x}}$ & $\triangle V C X 1$ & $\triangle V C X 2$ & $\triangle V C X 3$ & State \\
\hline \multirow[t]{8}{*}{3} & $\left|\Delta \mathrm{V}_{\mathrm{CX} 1}\right|>\left|\Delta \mathrm{V}_{\mathrm{CX} 3}\right|$ & $\geq 0$ & $\geq 0$ & - & - & $\mathrm{D}_{1}$ \\
\hline & & & $<0$ & - & - & $\mathrm{D}_{3}$ \\
\hline & & $<0$ & $\geq 0$ & - & - & $\mathrm{D}_{3}$ \\
\hline & & & $<0$ & - & - & $D_{1}$ \\
\hline & $\left|\Delta \mathrm{V}_{\mathrm{CX} 3}\right|>\left|\Delta \mathrm{V}_{\mathrm{CX} 1}\right|$ & $\geq 0$ & - & - & $\geq 0$ & $D_{2}$ \\
\hline & & & - & - & $<0$ & $D_{1}$ \\
\hline & & $<0$ & - & - & $\geq 0$ & $D_{1}$ \\
\hline & & & - & - & $<0$ & $\mathrm{D}_{2}$ \\
\hline \multirow[t]{12}{*}{2} & $\left|\Delta \mathrm{V}_{\mathrm{CX} 1}\right|>\left|\Delta \mathrm{V}_{\mathrm{CX} 3}\right|$ & $\geq 0$ & $\geq 0$ & - & - & $\mathrm{C}_{1}$ \\
\hline & $\&$ & & $<0$ & - & - & $\mathrm{C}_{2} / \mathrm{C}_{4}$ \\
\hline & $\left|\Delta \mathrm{V}_{\mathrm{CX} 1}\right|>\left|\Delta \mathrm{V}_{\mathrm{CX} 2}\right|$ & $<0$ & $\geq 0$ & - & - & $\mathrm{C}_{2} / \mathrm{C}_{4}$ \\
\hline & & & $<0$ & - & - & $\mathrm{C}_{1}$ \\
\hline & $\left|\Delta \mathrm{V}_{\mathrm{CX} 2}\right|>\left|\Delta \mathrm{V}_{\mathrm{CX} 1}\right|$ & $\geq 0$ & - & $\geq 0$ & - & $\mathrm{C}_{3} / \mathrm{C}_{1}$ \\
\hline & & & - & $<0$ & - & $\mathrm{C}_{2}$ \\
\hline & $\left|\Delta \mathrm{V}_{\mathrm{CX} 2}\right|>\left|\Delta \mathrm{V}_{\mathrm{CX} 3}\right|$ & $<0$ & - & $\geq 0$ & - & $\mathrm{C}_{2}$ \\
\hline & & & - & $<0$ & - & $\mathrm{C}_{3} / \mathrm{C}_{1}$ \\
\hline & $\left|\Delta \mathrm{V}_{\mathrm{CX} 3}\right|>\left|\Delta \mathrm{V}_{\mathrm{CX} 1}\right|$ & $\geq 0$ & - & - & $\geq 0$ & $\mathrm{C}_{2}$ \\
\hline & $\&$ & & - & - & $<0$ & $\mathrm{C}_{3}$ \\
\hline & $\left|\Delta \mathrm{V}_{\mathrm{CX} 3}\right|>\left|\Delta \mathrm{V}_{\mathrm{CX} 2}\right|$ & $<0$ & - & - & $\geq 0$ & $\mathrm{C}_{3}$ \\
\hline & & & - & - & $<0$ & $\mathrm{C}_{2}$ \\
\hline \multirow[t]{8}{*}{1} & $\left|\Delta \mathrm{V}_{\mathrm{CX} 2}\right|>\left|\Delta \mathrm{V}_{\mathrm{CX} 3}\right|$ & $\geq 0$ & - & $\geq 0$ & - & $\mathrm{B}_{3}$ \\
\hline & & & - & $<0$ & - & $\mathrm{B}_{1}$ \\
\hline & & $<0$ & - & $\geq 0$ & - & $\mathrm{B}_{1}$ \\
\hline & & & - & $<0$ & - & $\mathrm{B}_{3}$ \\
\hline & $\left|\Delta \mathrm{V}_{\mathrm{CX} 3}\right|>\left|\Delta \mathrm{V}_{\mathrm{CX} 2}\right|$ & $\geq 0$ & - & - & $\geq 0$ & $\mathrm{~B}_{1}$ \\
\hline & & & - & - & $<0$ & $\mathrm{~B}_{2}$ \\
\hline & & $<0$ & - & - & $\geq 0$ & $\mathrm{~B}_{2}$ \\
\hline & & & - & - & $<0$ & $\mathrm{~B}_{1}$ \\
\hline
\end{tabular}


The as shown in (1) are the possible change in voltages [11] for the given capacitor

$$
\text { Let, } \Delta \mathrm{Vcxi}=\mathrm{Vcxi}-\mathrm{Vcxi} \text {, ref }
$$

Where $\mathrm{i}=1,2$ and 3 and $\mathrm{x}=\mathrm{a}, \mathrm{b}$ and $\mathrm{c}$

$\mathrm{V}_{\mathrm{Cxi}}$ are capacitor voltages, $\mathrm{V}_{\text {cxiref }}$ are the monetary values

$\mathrm{V}_{\mathrm{cx} 3 \mathrm{ref}}=(3 \mathrm{Vdc} / 4)$, Vcxiref $=(\mathrm{Vdc} / 4)$ for i must be 1,2 , and 3.

VCxi should be set close to zero to accomplish capacitor voltage balancing. Table 1 gives what state should be employed to regulate the voltage of flying capacitors under various situations.

\section{SYNCHRONOUS REFERENCE FRAME CONTROLLER}

Controller SRF is a major module in the proposed test system which controls the multi-level inverter's output voltage. For the output voltage match to the grid voltage amplitude, phase, and frequency the SRF controller takes feedback from the grid three-phase voltages, currents, and DC link voltage at the input [20]-[22]. The structure of the SRF controller is given in Figure 3.

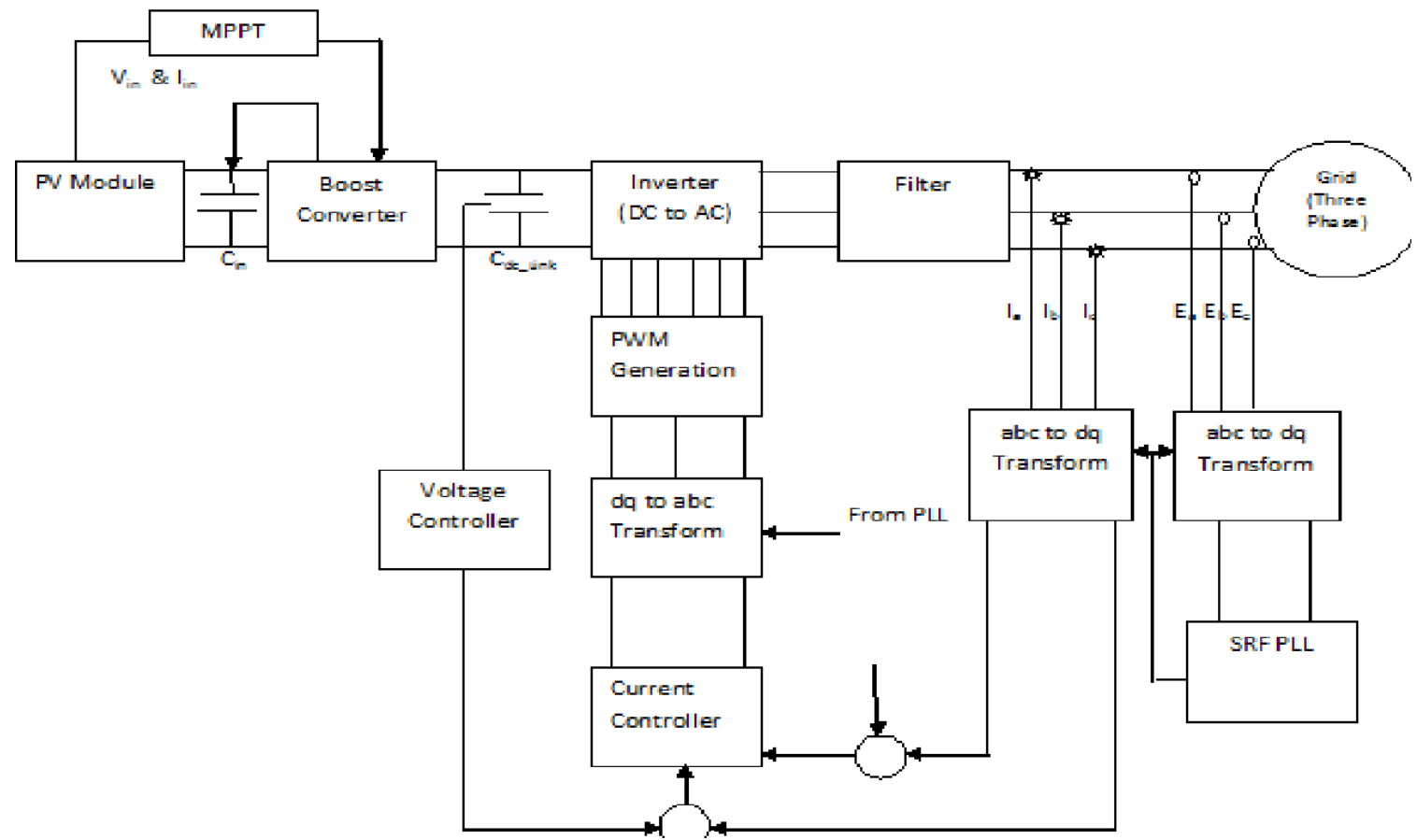

Figure 3. SRF control structure for PVA grid interconnection

The SRF controller uses Park's transformation for controlling the current of the inverter. The dq components of the currents are calculated for the PLL module [23]-[25] working in synchronization to the grid voltage. The dq axis calculation for the given controller is given in (2) and (3).

$$
\begin{aligned}
& {[U \alpha U \beta]=\frac{2}{3} *\left[1-\frac{1}{2}-\frac{1}{2} 0 \frac{\sqrt{3}}{2}-\frac{\sqrt{3}}{2}\right][U a U b U c]} \\
& {[U d U q]=[U \alpha U \beta][\operatorname{Cos} w t \operatorname{Sin} w t-\operatorname{Sin} w t \operatorname{Cos} w t]}
\end{aligned}
$$

In the above equations, the function $U$ denotes either three-phase voltages or currents at PCC. The voltage controller is a PI controller with input taken by comparison of DC voltage at the DC link capacitor and reference value given by the user. The output of the voltage controller is direct axis component reference and the quadrature axis reference component is considered to be 0 . The current controller generates the required reference dq voltage reference component with the PI controller in it. The reference dq voltage components (Ud* and $\mathrm{Uq}^{*}$ ) are converted to sinusoidal by inverse parks transformation [26]. The final three- 
phase sinusoidal reference waveforms are compared to phase disposition multi-carrier modulation technique for the generation of pulses for the novel five-level inverter. As the SRF controller uses PLL to generate the reference signals and the PLL is operated with grid voltage as feedback, the inverter operates in synchronization with the grid.

\section{PVA-MPPT MODULE}

The PVA is a DC source that generates power by converting solar irradiation to electrons. Each PV panel comprises p-type and n-type material with silicon doping to generate holes and electrons respectively. The DC voltage from the PVA is not always constant as the solar irradiation is variable with changes in climatic conditions [27]. The variable DC voltage cannot be used for the proposed inverter as input. Because with variation in the $\mathrm{DC}$ voltage the $\mathrm{AC}$ amplitude changes creating sags in the grid and also create circulating currents resulting in harmonics generation. Ignoring this issue might damage the source, loads, and modules linked to the electrical grid system [28], [29]. Therefore, for constant DC voltage generation, the PVA connected to a stabilizing DC regulated booster converter controlled by the MPPT technique for maintaining the output voltage at a specified value [30]. A DC-DC booster converter is utilized for this purpose to increase the input voltage to the inverter as the AC loads operate at high voltages. The PVA connected to the booster converter schematic can be demonstrated in Figure 4.

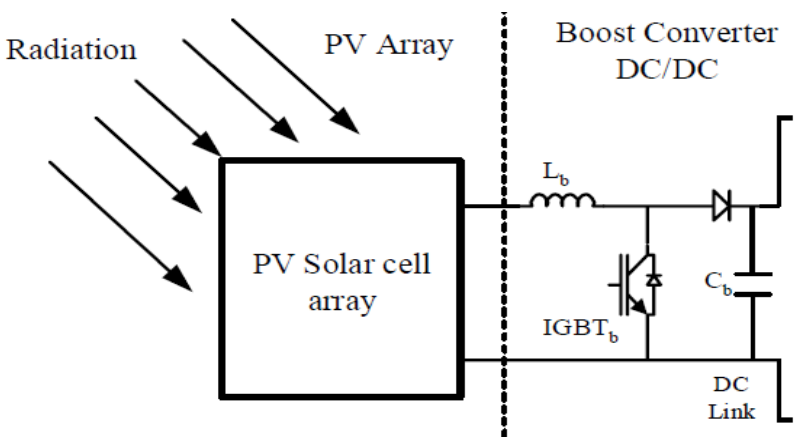

Figure 4. PVA with booster converter module

The converter comprises of single IGBT switch controlled by comparing duty ratios, a highfrequency pulse is created and compared to high-frequency triangular carrier waveform. IGBT switch duty ratio is generated by the Incremental conductance MPPT algorithm [24]. This algorithm is considered to be robust and operates with a faster response rate as contrast to the traditional MPPT P\&O algorithm. The ratio comparison errors of voltage and current of the PVA decides the increase or decrease in duty ratio value. In general, the duty ratio increases when there is a drop in solar irradiation, and the duty ratio decrease when there is a rise in solar irradiation.

\section{SIMULATION RESULTS AND DISCUSSION}

\subsection{Case studies for different loads}

\subsubsection{R-load}

PVA as a renewable source connected to a novel five-level inverter controlled by an SRF controller interconnected to a three-phase grid is modeled in MATLAB/Simulink toolbox. From Figure 5, as the irradiance changed from $1000 \mathrm{w} / \mathrm{m}^{2}$ to $500 \mathrm{w} / \mathrm{m}^{2}$, we can observe that, the voltage and current of the photo voltaic module are reduced. During this change the power output of one PVA module also reduced. The PVA rating for specific solar irradiation is given in Table 2. From the Table 2 it is observed that there is a reduction of output voltage current and power at different solar irradiances. The three phase voltages and currents for R-load is shown in Figure 6(a), Figure 6(b) shows the active power of $50 \mathrm{KW}$ and Figure 6(c) gives the voltage THD of $0.05 \%$. With FFT analysis tool the THD of one phase is located at the same connection point is determined and shown in Table 3. From Table 3, \% THD of output phase voltages differentLoads without SRF controller are higher, but \%THD of output phase voltages for R, RL, and motorloads with SRF controller is further reduced by eliminating the harmonics. 

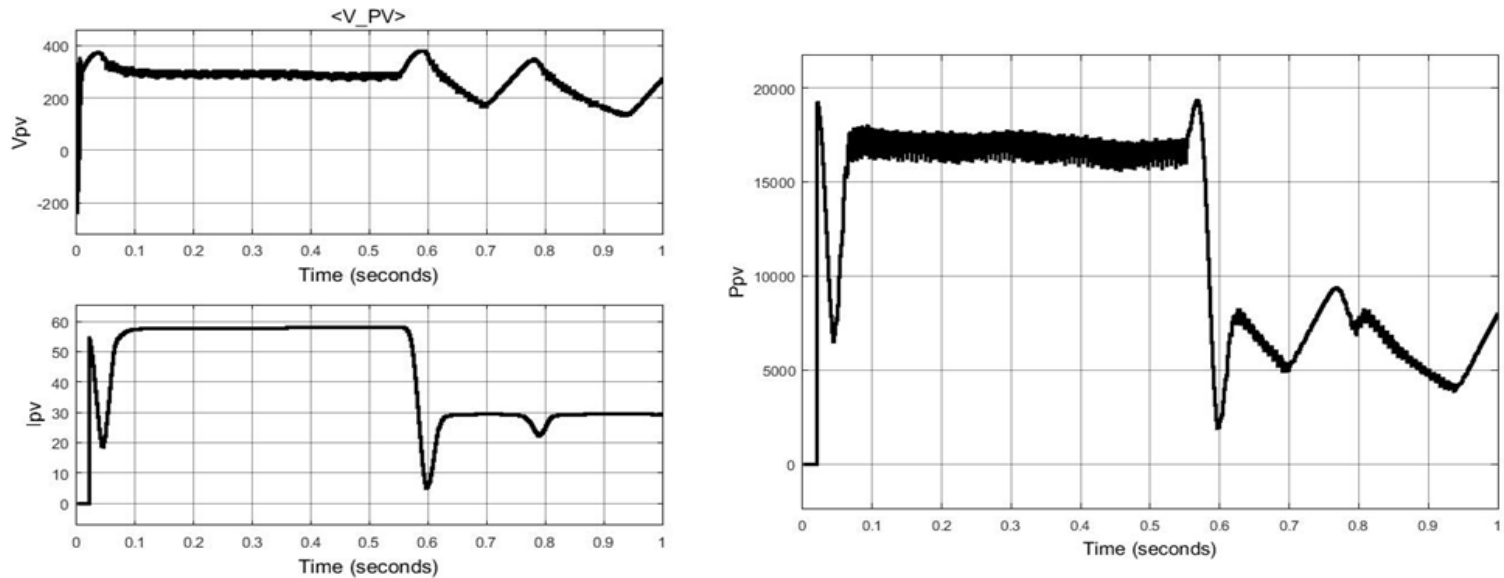

Figure 5. Voltage, current power of the PV cell of one module
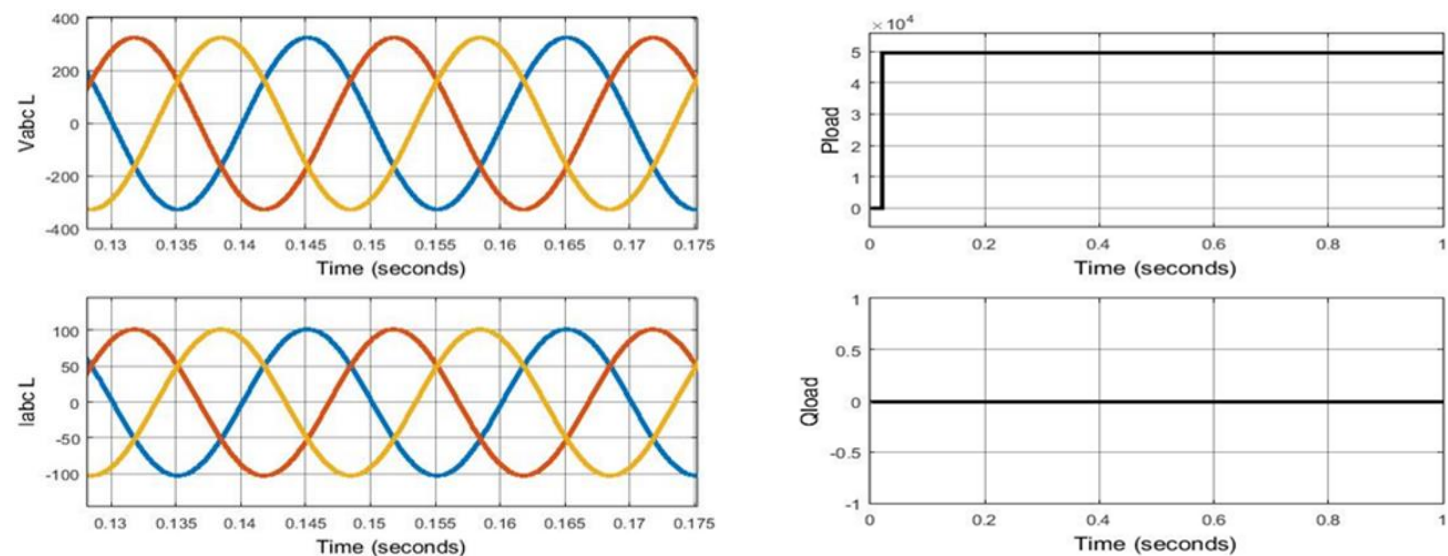

(a)

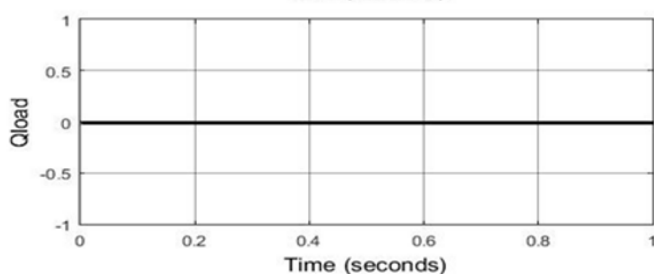

(b)

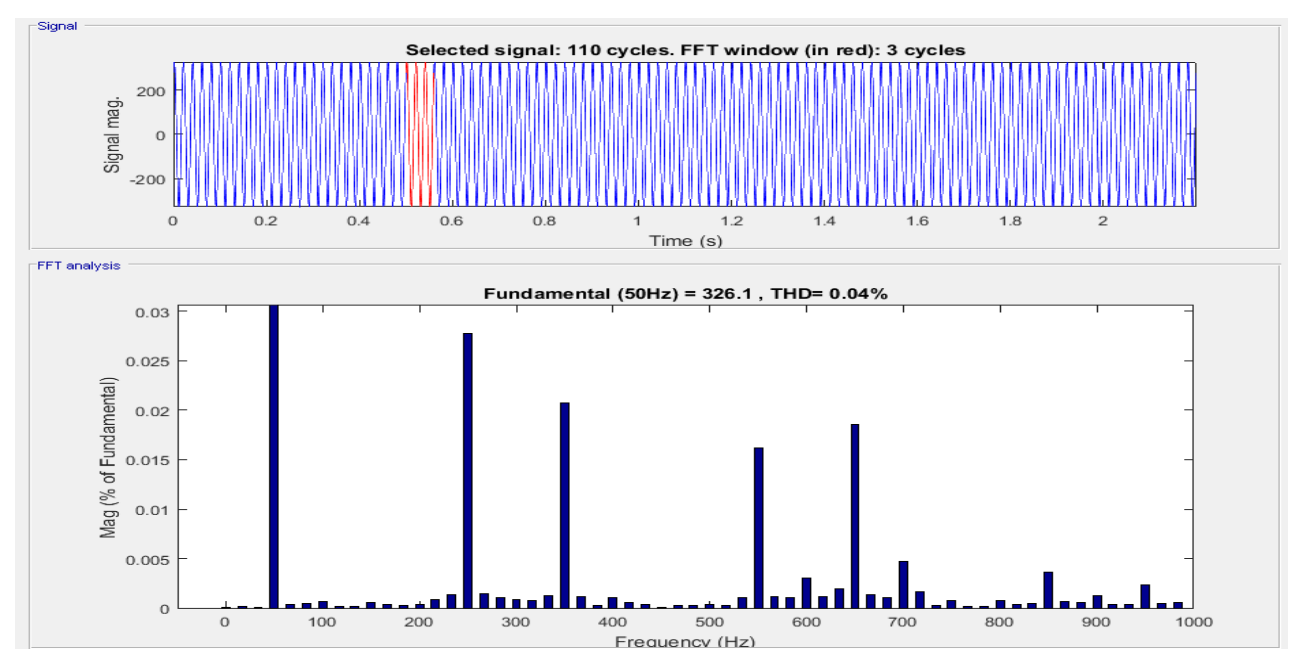

(c)

Figure 6. The three phase voltages and currents (a) $V_{a b c}$ and $I_{a b c}(b)$ load active power reactive power with the only $50 \mathrm{KW}$ and (c) $\mathrm{THD}=0.05 \%$ for $\mathrm{V}_{\mathrm{abc}}$ with R-load

Table 2. $\mathrm{V}_{\mathrm{pv}}, \mathrm{I}_{\mathrm{PV}}, \mathrm{P}_{\mathrm{PV}}, \mathrm{V}_{0}$ values at different solar irradiances

\begin{tabular}{cccccc}
\hline Solar irradiance & Temperature & $\mathrm{V}_{\mathrm{pv}} / 2$ & $\mathrm{I}_{\mathrm{pv}} / 2$ & $\mathrm{P}_{\mathrm{pv}} / 2$ & $\mathrm{~V}_{0} / 2$ \\
\hline $1000 \mathrm{w} / \mathrm{m}^{2}$ & $40^{\circ}$ & $300 \mathrm{v}$ & $58.13 \mathrm{~A}$ & $16 \mathrm{kw}$ & $300 \mathrm{v}$ \\
$500 \mathrm{w} / \mathrm{m}^{2}$ & $20^{\circ}$ & $255.3 \mathrm{v}$ & $29.15 \mathrm{~A}$ & $7.4 \mathrm{kw}$ & $254.4 \mathrm{v}$ \\
\hline
\end{tabular}


Table 3. Output phase voltage thd of inverter side for R, RL, and induction motor-load

\begin{tabular}{lccc}
\multirow{3}{*}{ Case studies } & \multicolumn{3}{c}{$\%$ THD of Ph-Ph output voltage } \\
\cline { 2 - 3 } & \multicolumn{2}{c}{ Without SRF controller } & \multirow{2}{*}{ With SRF controller } \\
\cline { 2 - 3 } & without LC-filter & with LC-filter & \\
\hline R-load & $25.35 \%$ & $0.86 \%$ & $0.06 \%$ \\
RL-load & $48.75 \%$ & $0.70 \%$ & $0.07 \%$ \\
Induction motor-load & $308.19 \%$ & $52.57 \%$ & $0.05 \%$ \\
\hline
\end{tabular}

\subsubsection{RL-load}

The three phase voltages and currents with their THD for RL load is shown in the three phase voltages and currents for RL-load is shown in Figure 7(a), Figure 7(b) shows the active power of $50 \mathrm{KW}$, reactive power of and $30 \mathrm{KVAR}$ with 0.85 power factor and Figure 7 (c) gives the voltage THD of $0.05 \%$ for RL-load. The THD is much less than $1 \%$ for $\mathrm{V}_{\mathrm{abc}}$ with the help of the SRF controller as compared to the THD without the SRF controller. As the controller takes feedback from the grid current and voltage. Pulses are generated by the inverter is synchronised to the grid voltage. The frequency, phase and amplitude of the inverter are tuned to same values of the grid voltage to achieve shychronization. This reduces the harmonics generation in the currents and voltages of the grid and the inverter as shown in Figure 7.
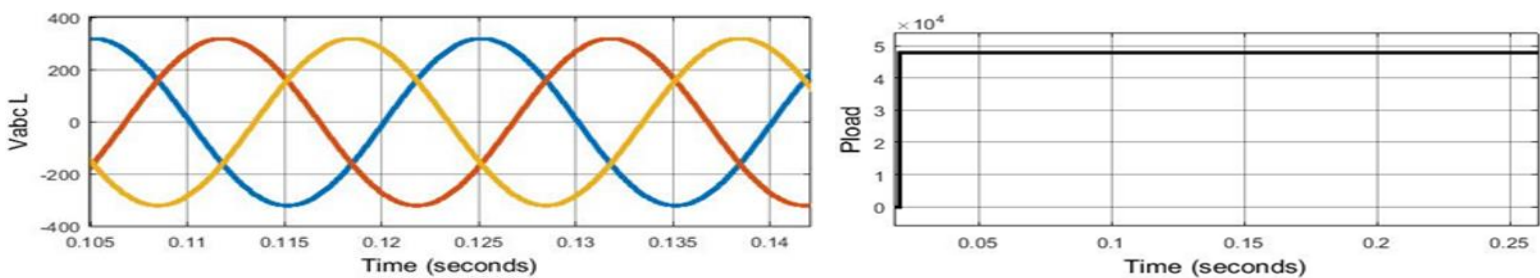

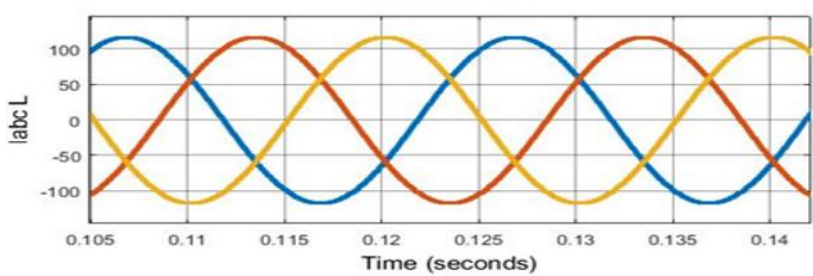

(a)

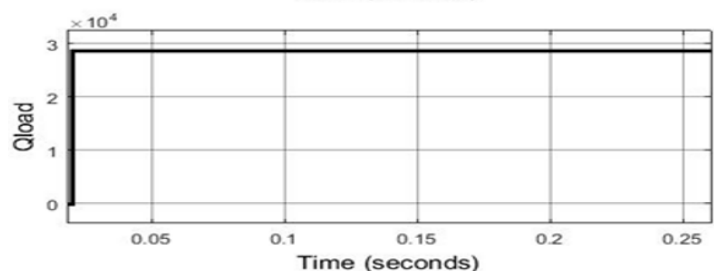

(b)
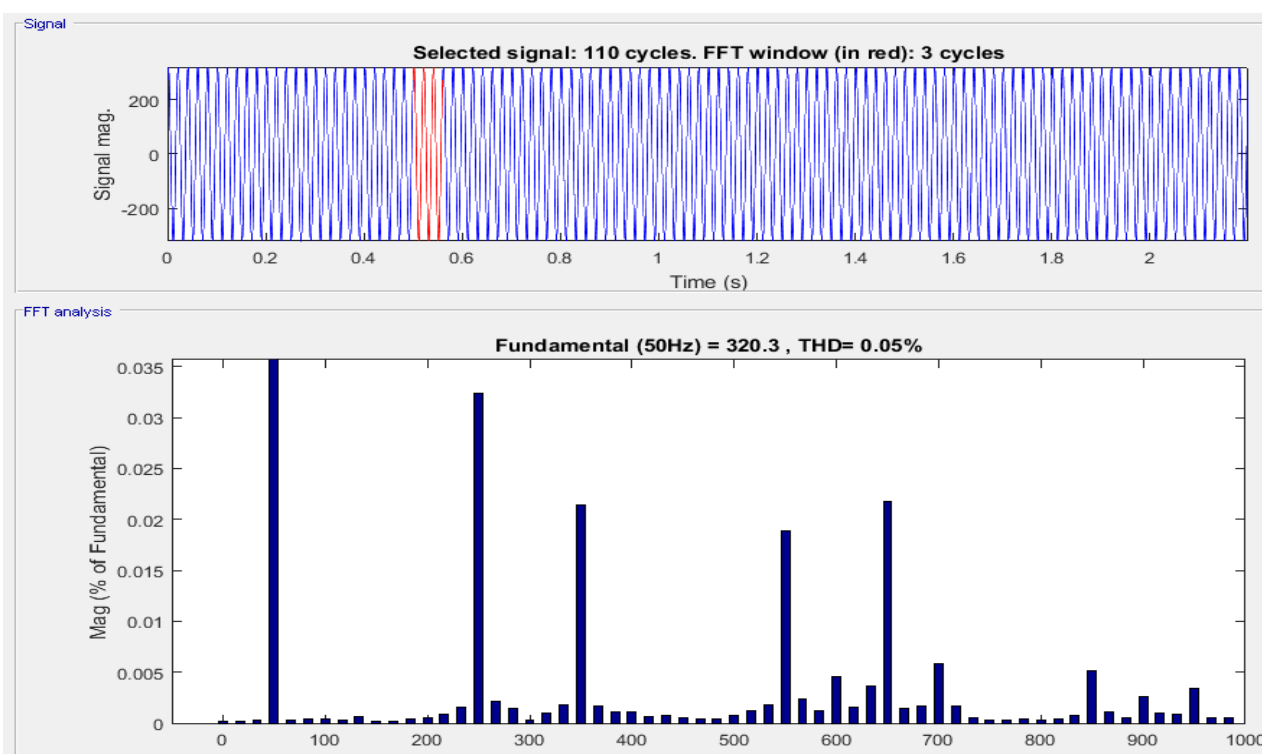

(c)

Figure 7. The three phase voltages and currents (a) $V_{a b c}$ and $I_{a b c}(b)$ load active power reactive power with the only $50 \mathrm{KW}$ and $30 \mathrm{KVAR}$ with 0.85 power factor and (c) $\mathrm{THD}=0.05 \%$ for $\mathrm{V}_{\mathrm{abc}}$ with RL-load 
The grid system is interconnected with different loads through a load transformer $11 \mathrm{kV} / 440 \mathrm{~V}$ operating a static load of $1 \mathrm{~kW}$ and a dynamic load induction motor connected in parallel. From the Figure 5, it is seen that, as the irradiance drops from $1000 \mathrm{w} / \mathrm{m}^{2}$ to $500 \mathrm{w} / \mathrm{m}^{2}, \mathrm{P}_{\mathrm{pv}}$ decreases from 0.6 seconds onwards. So, to balance it, grid is injecting power to the system from 0.6 seconds onwards.

\section{CONCLUSION}

Successful implementation of novel five-level voltage source inverter controlled by SRF controller with PD multi-carrier modulation technique is simulated. The interconnection to the grid through the inverter is synchronized and the power from the PVA is injected into the system compensating the loads connected at PCC. The system is tested for both static and dynamic load conditions and results show the reduction of output phase voltage THDs within the permissible limit $(<5 \%)$. A comparative analysis is carried out with different loads like R, RL and motor load determining THD of each case are presented. Injection of maximum power generated by the PVA to the grid through novel five level inverter with reduced harmonics is achived using SRF controller. The system can be further updated with multiple renewable sources that can be connected at the input to the inverter and an optimal controller can be utilized for better voltage and power stability in the system. An overview of the objectives achieved is given below. Power from renewable source PVA is efficiently injected into the grid with synchronization. Reduction of harmonic content in voltages during different load operations

\section{REFERENCES}

[1] M. E. Malah, A. B. Razzouk, M. Guisser, E. Abdelmounim, and M. Madark, "Backstepping based power control of a three-phase Single-stage Grid-connected PV system," International Journal of Electrical and Computer Engineering (IJECE), vol. 9, no. 6, pp. 4738-4748, 2019, doi: 10.11591/ijece.v9i6.pp4738-4748.

[2] A. Sangwongwanich and F. Blaabjerg, "Mitigation of Interharmonics in PV Systems With Maximum Power Point Tracking Modification," IEEE Transactions on Power Electronics, vol. 34, no. 9, pp. 8279-8282, 2019, doi: 10.1109/TPEL.2019.2902880.

[3] A. Rahnamaei and M. Salimi, "A Novel Grid Connected Photovoltaic System," Bulletin of Electrical Engineering and Informatics, vol. 5, no. 2, pp. 133-143, 2016, doi: 10.11591/eei.v5i2.523.

[4] A. Mahammedi, A. Kouzou, A. Hafaifa, and B. Talbi, "A new technique for a good efficiency of photovoltaic system under fast changing solar irradiation,” Electrotehnica, Electronica, Automatica (EEA), vol. 67, no. 4, pp. 12-19, 2019.

[5] A. Raj and S. S. Dash, "Grid connected hybrid energy system with Maximum power point tracking technique," International Conference on Energy Efficient Technologies for Sustainability, 2013, pp. 338-342, doi: 10.1109/ICEETS.2013.6533406.

[6] S. Mahjoub, M. Ayadi, F. Masmoudi and N. Derbel, "Control of Hybrid Renewable Energy System Based on MPPT Strategy Technique," 15th International Multi-Conference on Systems, Signals \& Devices (SSD), 2018, pp. 1280-1286, doi: 10.1109/SSD.2018.8570450.

[7] B. Madaci, R. Chenni, E. Kurt, and K. E. Hemsas, "Design and control of a stand-alone hybrid power system," International Journal of Hydrogen Energy, vol. 41, no. 29, pp. 12485-12496, 2016, doi: 10.1016/j.ijhydene.2016.01.117.

[8] Y. Errami, M. Ouassaid, and M. Maaroufi, "A performance comparison of a nonlinear and a linear control for grid Connected PMSG wind energy conversion system," International Journal of Electrical Power \& Energy Systems, vol. 68, pp. 180-194, 2015, doi: 10.1016/j.ijepes.2014.12.027.

[9] B. Sirisha and P. S. Kumar, "SVPWM Based Generalized Switching Schemes for Seven Level DCMLI Including Over Modulation Operation - FPGA Implementation," TENCON 2019-2019 IEEE Region 10 Conference (TENCON), 2019, pp. 2135-2142, doi: 10.1109/TENCON.2019.8929380.

[10] B. Sirisha and P. S. Kumar, "A simplified space vector PWM for cascaded H-Bridge inverter including over modulation operation," IEEE Annual India Conference (INDICON), 2016, pp. 1-6, doi: 10.1109/INDICON.2016.7839038.

[11] S. Fan, Y. Yu, Y. Zhang and H. Yang, "Multi-mode Synchronized PWM Schemes for three-level NPC Inverter," 22nd International Conference on Electrical Machines and Systems (ICEMS), 2019, pp. 1-5, doi: 10.1109/ICEMS.2019.8921689.

[12] V. A. Kumar and M. Arounassalame, "Comparison of CHB Multi level inverters using Level shifted Modulation techniques with closed loop PI control," 4th International Conference on Electrical Energy Systems (ICEES), 2018, pp. 168-172, doi: 10.1109/ICEES.2018.8443288.

[13] B. Sirisha, P. S. Kumar, "A Simplified and Generalized Space Vector Pulse Width Modulation MethodIncluding Over Modulation Zone for Seven Diode Clamped Inverter - FPGA Implementation," International Journal of Power Electronics, vol. 10, no.4, pp. $350-366,2019$

[14] W. Jiang, X. Huang, J. Wang, J. Wang and J. Li, “A Carrier-Based PWM Strategy Providing Neutral-Point Voltage Oscillation Elimination for Multi-Phase Neutral Point Clamped 3-Level Inverter," IEEE Access, vol. 7, pp. 124066-124076, 2019, doi: 10.1109/ACCESS.2019.2938623.

[15] R. Abdullah, N. A. Rahim, S. R. S. Raihan, and A. Z. Ahmad, "Five-Level Diode-Clamped Inverter with Three-Level Boost Converter," IEEE Transactions on Industrial Electronics, vol. 61, no. 10, pp. 5155-5163, 2014, doi: 10.1109/TIE.2013.2297315.

[16] Z. Xu, X. Zheng, T. Lin, J. Yao, and A. Ioinovici, "Switched-capacitor multi-level inverter with equal distribution of the capacitors discharging phases," Chinese Journal of Electrical Engineering, vol. 6, no. 4, pp. 42-52, 2020, doi: 10.23919/CJEE.2020.000029.

[17] M. Ranjit., V. R. Babu. and S. R. Jalluri, "Performance Analysis of Multicarrier PWM Techniques for Dual Inverter Fed Open End Winding Induction Motor Drive," 2nd International Conference on Power and Embedded Drive Control (ICPEDC), 2019, pp. 1823, doi: 10.1109/ICPEDC47771.2019.9036509.

[18] O. A. Lysenko and I. Y. Marchinskiy, "Multi-level Inverters Application Features for Medium Voltage Electric Drives," Dynamics of Systems, Mechanisms and Machines (Dynamics), 2018, pp. 1-6, doi: 10.1109/Dynamics.2018.8601464.

[19] M. M. Renge and H. M. Suryawanshi, "Five-Level Diode Clamped Inverter to EliminateCommon Mode Voltage and Reduce dv/dt inMedium Voltage Rating Induction Motor Drives," IEEE Transactions on Power Electronics, vol. 23, no. 4, pp. 1598-1607, 2008, doi: 10.1109/TPEL.2008.925423. 
[20] Y. Han, X. Fang, P. Yang, C. Wang, L. Xu, and J. M. Guerrero, "Stability Analysis of Digital-Controlled Single-Phase Inverter with Synchronous Reference Frame Voltage Control," IEEE Transactions on Power Electronics, vol. 33, no. 7, pp. 6333-6350, 2018, doi: 10.1109/TPEL.2017.2746743.

[21] B. Sirisha and P. Satish Kumar "Three Phase Two Leg Neutral Point Clamped Converter with output DC Voltage Regulation and Input Power Factor Correction," International Journal of Power Electronics and Drive System, vol . 2, no. 2, pp. 138-150, 2012.

[22] L. Shang, W. Zhu and Z. Li, "A control method of PV grid-connected inverter under grid voltage unbalanced drops," Chinese Control And Decision Conference (CCDC), 2018, pp. 6482-6486, doi: 10.1109/CCDC.2018.8408269.

[23] S. Chatterjee and S. Chatterjee, "Simulation of synchronous reference frame PLL based grid connected inverter for photovoltaic application," 1st Conference on Power, Dielectric and Energy Management at NERIST (ICPDEN), 2015, pp. 1-6, doi: 10.1109/ICPDEN.2015.7084493.

[24] X. Quan and A. Q. Huang, "PI-Based Synchronous Reference Frame Frequency-Locked Loop," IEEE Transactions on Industrial Electronics, vol. 68, no. 5, pp. 4547-4553, 2021, doi: 10.1109/TIE.2020.2985002.

[25] B. Sirisha, "A grid interconnected nested neutral point clamped inverter with voltage synchronization using synchronous reference frame controller," International Journal of Applied Power Engineering, vol. 10, no. 4, 2021, pp. 364-372.

[26] A. M. Diab et al., "Fast and Simple Tuning Rules of Synchronous Reference Frame Proportional-Integral Current Controller," IEEE Access, vol. 9, pp. 22156-22170, 2021, doi: 10.1109/ACCESS.2021.3054845.

[27] R. B. Bollipo, S. Mikkili and P. K. Bonthagorla, "Hybrid, optimal, intelligent and classical PV MPPT techniques: A review," CSEE Journal of Power and Energy Systems, vol. 7, no. 1, pp. 9-33, 2021, doi: 10.17775/CSEEJPES.2019.02720.

[28] F. M. G. Longatt, "Model of photovoltaic module in Matlab," 2do congresoiberoamericano de estudiantes de ingenieriacute; a eléctrica, electrónica y computación, ii cibelec 2005, 2005, pp. 1-5.

[29] S. Bhattacharyya, D. S. Kumar P, S. Samanta and S. Mishra, "Steady Output and Fast Tracking MPPT (SOFT-MPPT) for P\&O and InC Algorithms," IEEE Transactions on Sustainable Energy, vol. 12, no. 1, pp. 293-302, 2021, doi: 10.1109/TSTE.2020.2991768.

[30] S. Selvakumar, M. Madhusmita, C. Koodalsamy, S. P. Simon and Y. R. Sood, "High-Speed Maximum Power Point Tracking Module for PV Systems," IEEE Transactions on Industrial Electronics, vol. 66, no. 2, pp. 1119-1129, 2019, doi: 10.1109/TIE.2018.2833036.

\section{BIOGRAPHIES OF AUTHORS}

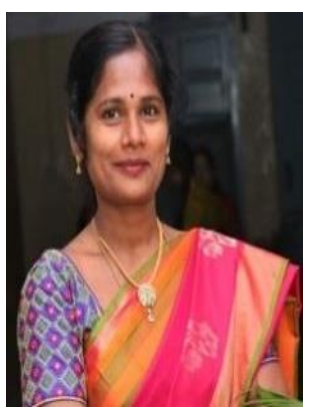

Bogimi Sirisha (D) SC P She holds a B.E. in Electrical Engineering from Osmania University, M. Tech Power Eelectronics from JNTUH in 2003, and a Ph.D. degree from Osmania University 2018. She has over 16 years of experience in research and teaching and is currently employed as an Associate Professor in Electrical Department, Engineering College, Osmania University, Hyderabad, India. She has published various articles in international and national journal publications and conferences. Multilevel inverters, power electronics and drives, renewable energy applications and special electrical machines are among her research interests. Osmania University awarded her a Ph.D. in the field of multilevel inverters. She can be contacted at email: sirishab@osmania.ac.in.

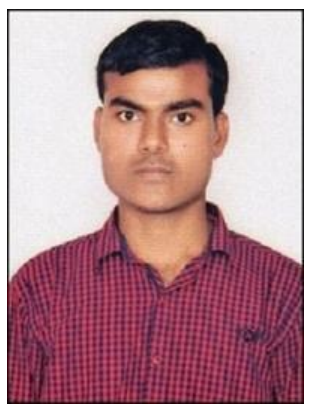

Mohd Abdul Nazeemuddin (iD I8 SC P Master of Engineering (M.E.) completed from University College of Engineering (A), Osmania University, Hyderabad, Telangana, India. Persuing $\mathrm{Ph}$. D degree in renewable energy applications from Osmania University. He can be contacted at email: nazeemuddinma201@gmail.com. 